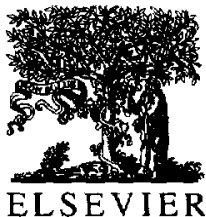

Talanta $43(1996) 169-175$

\title{
Determination of trace nitrite ion in water by spectrophotometric method after preconcentration on an organic solvent-soluble membrane filter
}

\author{
Xuexin Gu a, Tianze Zhou ${ }^{\text {a.* }}$, Dayong Qi ${ }^{\text {b }}$ \\ "Capital Normal University, Beijing 100037. China \\ ${ }^{b}$ Research Centre of Eco-enciromment, Academia Sinica, Beijing 100085. China
}

Received 25 April 1995; revised 5 July 1995; accepted 7 July 1995

\begin{abstract}
A simple and rapid preconcentration technique, based on collecting trace nitrite on a membrane filter and dissolving the membrane filter in an organic solvent, has been applied to its spectrophotometric determination in water. At $\mathrm{pH} 2.0$. nitrous acid diazotizes with $p$-aminoacetophenone. which is then coupled with $N$-(1-naphthyl)ethylenediamine, at the same $\mathrm{pH}$. The azo dye formed is collected on a $0.45 \mu \mathrm{m}$ nitrocellulose filter at $\mathrm{pH} 4.7$ as its ion associate with dodecyl sulfate. The ion associate and filter are dissolved in a small volume of 2-methoxyethanol (methylcellosolve), and acidized with $0.05 \mathrm{ml}$ of $2 \mathrm{M}$ hydrochloric acid and the absorbance of the resulting solution is measured at $555 \mathrm{~nm}$ against a reagent blank. Detection limits better than $0.1 \mu \mathrm{g} / \mathrm{dm}^{-3}$ as $\mathrm{NO}_{2}^{-}$can be achieved. The ions normally present in water do not interfere when sodium metaphosphate is added as a masking agent. The proposed method has been applied to the analysis of water samples from several sources, the recoveries of the nitrite added to the samples are quantitative, and results found are satisfactory.
\end{abstract}

Keywords: Nitrite: Photometric determination; Preconcentration; Soluble filter

\section{Introduction}

It has become very important to determine trace amounts of nitrite in environmental protection, some chemical processes, the food industry and hygiene applications. Many reagents for the spectrophotometric determination of nitrite at very low concentrations have been reviewed and

\footnotetext{
* Corresponding author. Fax: (86)10-841-6837.
}

usually employed with one of the modifications of the Griess-Ilosvay reactions [1]. The procedure using the Griess-Ilosvay reaction seems to be a satisfactory one, but in order to enhance sensitivity extraction has been proposed. It was reported [2] that nitrous acid diazotizes $p$-aminoacetophenone, which is then coupled with m-phenylenediamine; the 2,4-diamino-4'-acetyl-azobenzene formed is extracted into toulene at $\mathrm{pH} \mathrm{9,} \mathrm{and} \mathrm{the}$ absorbance measured at $450 \mathrm{~nm}$. The molar absorptivity is about $2.3 \times 10^{4} \mathrm{~mol}^{-1}$. An improve- 
ment to this extraction system was later suggested by Zhou and Xie [3]. It was reported that nitrite diazotizes with $p$-aminoacetophenone at $\mathrm{pH} 2.0$. and is then coupled with $N$-(1-naphthyl)-ethyldiamine; the azo dye formed is further associated with $\beta$-naphthyl sulfonic acid in acid medium and extracted into $n$-butanol in the presence of aluminium nitrate and salted-out at the same $\mathrm{pH}$; the absorbance of the extract is measured at $555 \mathrm{~nm}$ and the molar absorptivity is about $4.8 \times 10^{4} \mathrm{I} \mathrm{mol}^{-1} \mathrm{~cm}^{-1}$.

Though solvent extraction of the nitrite has achieved considerable success in increasing the sensitivity and improving the detection limit to better than $10 \mu \mathrm{g} \mathrm{dm}^{-3}$, the enrichment factor is usually limited by the mutual solubility of organic solvent and water. It is also especially tedious to twice introduce pollution of the solvent.

Recently, solvent-soluble membrane filters (MFs) have been reported for the rapid and simple preconcentration of trace components in water [4-6]. This new pre-concentration technique, which is based on collecting the analyte on a membrane filter and dissolving the membrane in an organic solvent, resembles solvent extraction but has many advantages over solvent extraction. Maximum possible concentration factors are not limited by the mutual solubility of water and organic solvent. Concentration factors greater than 100 can easiy be obtained.

In previous studies, this preconcentration technique has been used by one of the authors in place of solvent extraction for the determination of nitrite in water [7]. A ten-fold preconcentration (with $50 \mathrm{ml}$ sample volume) can be done in a short time (with high sample throughout $>50 \mathrm{ml} \mathrm{min}^{-1}$ ) with a detection limit of $0.5 \mu \mathrm{g} \mathrm{dm}^{-3}$ as $\mathrm{NO}_{2}^{-}$. Nitrite ion is converted to 4-sulfobenzenediazonium ion and then coupled with 1-aminonaphthalene to form an azo dye, which is collected on a nitrocellulose membrane filter as its ion-associate with benzyldimethyltetradecylammonium ion at about $\mathrm{pH} 4.7$. The resulting compound is dissolved in methyl-cellosolve.

In the present investigation, the authors developed a more sensitive and selective preconcentration-spectrophotometric method for trace nitrite ion in water samples by applying the principle mentioned above. The main improvements on this method have been suggested.

The conditions for the formation of a coloured ion associate are similar to those reported in earlier work on extraction of nitrite [3]. The volumes of reagent added are varied in proportion to the sample volume. The most attractive features of the new pre-concentrated methods are diazotizing with $p$-aminoacetophenone which has a hydrophobic substitutive group, associating with an anion surfactant having a long-chain alkyl such as sodium dodecyl sulfatc and collecting the ion associate in a acid medium. Therefore the sensitivity and selectivity of the present method are enhanced. The detection limit is $0.1 \mu \mathrm{g} \mathrm{dm}{ }^{-3} \mathrm{NO}_{2}^{-}$ on a $3 \sigma$ basis under 100 -fold preconcentration (with $500 \mathrm{ml}$ sample volume), and Beer's law is obeyed in the range $0.1-1.0 \mu \mathrm{g} \mathrm{NO}_{2}^{-}$in $5 \mathrm{ml}$ of solvent with excellent reproducibility. In this paper optimum conditions of the experiment and analytical results are reported.

\section{Experimental}

\subsection{Reagents}

Standard nitrite solution

Dissolve $0.492 \mathrm{~g}$ anhydrous sodium nitrite (dried in desiccator for $4 \mathrm{~h}$ ) in $100 \mathrm{ml}$ water $(1.00 \mathrm{mg}$ nitrogen or $3.28 \mathrm{mg}$ nitrite per $\mathrm{ml})$. Prepare a working solution by suitable dilution and store in a brown bottle in a refrigerator. Standardize iodometrically before using.

\section{p-Aminoacetophenone hydrochloride solution}

Prepare a $0.5 \%(\mathrm{w} / \mathrm{v})$ solution in $1+9$ hydrochloric acid, and store in a brown bottle: $N$-(1-naphthyl)-ethylenediamine dihydrochloride solution.

Dissolve $0.5 \mathrm{~g} N$-(1-naphthyl)-ethylenediamine dihydrochloride in $100 \mathrm{ml}$ of $1+99$ hydrochloric acid.

\section{Sodium dodecyl sulfate solution}

Prepare a $1.00 \times 10^{-3} \mathrm{M}$ aqueous solution. Dissolve $0.288 \mathrm{~g}$ sodium dodecyl sulfate in 11 water. 


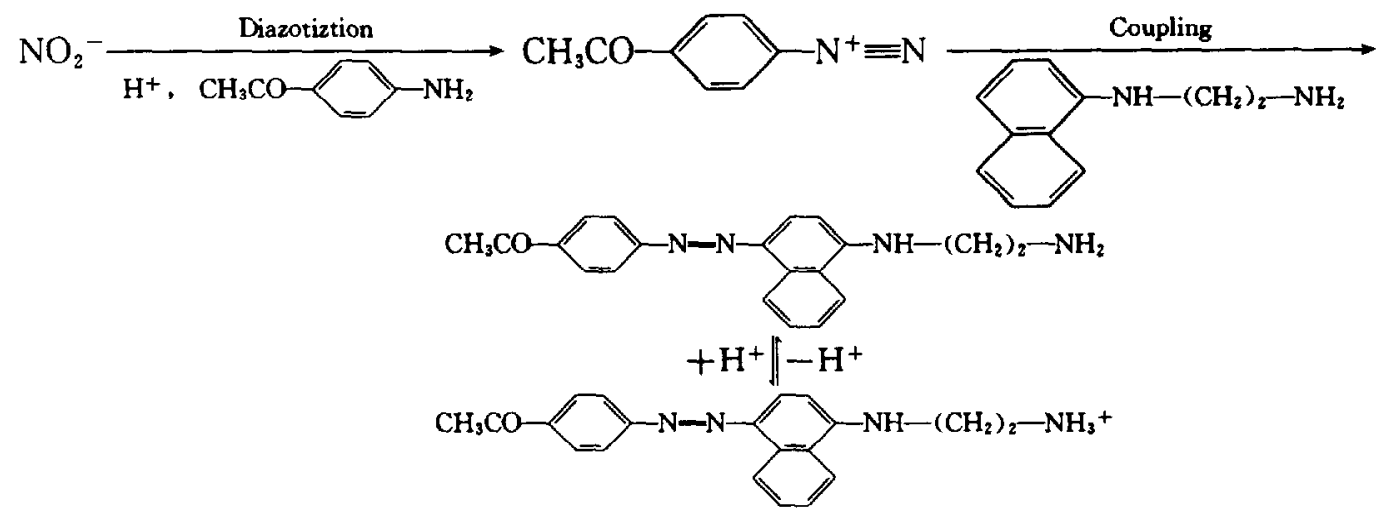

Fig. 1. Azo dye formation from nitrite, $p$-amino acetophenone and $N$-(1-naphthyl)-ethylenediamine.

\section{$\beta$-Naphthyl sulfonic acid $0.5 \%(w / v)$}

Dissolve $0.5 \mathrm{~g} \beta$-naphthyl sulfonic acid in $100 \mathrm{ml}$ water. Adjust to $\mathrm{pH} 6.0$ with sodium hydroxide solution.

Sodium metaphosphate solution: $5.0 \%(\mathrm{w} / \mathrm{v})$.

Unless stated otherwise, all reagents used are of analytical pure grade, and all solutions are diluted with nitrite-free water, which is obtained by distilling alkaline permanganate-distilled water using an all-glass distillation apparatus.

\subsection{Apparatus}

A UV-visible spectrophotometer UV-265 Model (Shimadzu, Japan), visible spectrophotometer 723 Model (Shanghai Third Analytical Instruments Factory, China), a pH Meter pHs-2 Model (Shanghai Second Analytical Instruments Factory, China) were used.

Membrane filters and holder: Most of the data presented in this paper were obtained with a nitrocellulose membrane $(25 \mathrm{~mm}$ in diameter, $0.45 \mu \mathrm{m}$ pore size, Adjective Factory of Chemical Engineering College of Beijing, Beijing 100029). A Toyo KG-25 filter holder (effective filtration area $1.3 \mathrm{~cm}^{2}$ ) was used.

\subsection{Procedure}

Add about $50 \mathrm{ml}$ of sample solution containing $0.1-1.0 \mu \mathrm{g}$ nitrite- $\mathrm{N}$ to a $150 \mathrm{ml}$ beaker. Add $1.0 \mathrm{ml}$ of $p$-aminoacetophenone hydrochloride solution and adjust to $\mathrm{pH} 2.0$ with either sodium acetate solution or hydrochloric acid. After 15 min standing at room temperature, add $1.0 \mathrm{ml}$ of $N$-(1-naphthyl)-ethylenediamine dihydrochloride solution and swirl. Add $2.0 \mathrm{ml}$ of sodium dodecyl sulfate solution and mix thoroughly again. Filter off the ion associate on the membrane filter, and wash the membrane with about $10 \mathrm{ml}$ of water. Dissolve the filter in $5 \mathrm{ml}$ of 2-methoxyethanol and acidize with $0.05 \mathrm{ml} 2 \mathrm{M}$ hydrochloric acid. Absorbance due to the associate in the solvent is measured in a $10 \mathrm{~mm}$ cell at $555 \mathrm{~nm}$ against a reagent blank.

\section{Results and discussion}

\subsection{Reactions for colour development}

In an acidic solution, nitrite reacts with a primary aromatic amine to produce diazonium salt, which in turn couples with an aromatic amine or phenol to form a coloured azo dye. In the orignal Griess reaction, sulfanilic acid was used and diazotized, but the azo compound formed cannot be collected quantitatively by the membrane filter becauase of the hydrophilic nature of the sulfonic group. By using $p$-aminoacetophenone in place of sulfanilic acid [2], the hydrophobic ability of the azo compund is enhanced, favouring collection on a membrane filter. The reactions for colour development are as shown in Fig. 1. 


\subsection{Absorption spectra}

Absorption maximum of the azo compound formed by diazotization of nitrous acid with $p$ aminoacetophenone and its coupling with $N$-(1naphthyl)-ethylenediamine in aqueous solution is $543 \mathrm{~nm}$; that of the ion associate in organic solvent is at $480 \mathrm{~nm}$ and that of the species in organic solvent after acidation is at $555 \mathrm{~nm}$. All absorbance measurements of the extract are made at the latter wavelength. Absorption spectra are shown in Fig. 2.

\subsection{Selection of counter ion}

In previous work [7] nitrite is converted to 4-sulfobenzendiazonium ion, which is then coupled with 1-aminonaphthalene to form an azo dye as in the conventional method, and the azo dye formed is collected on a nitrocellulose filter as its ion associate with a larger cation, benzyldimethyltetradecyl ammonum ion, at about $\mathrm{pH} 4.7$ (acetate buffer). Collection is poor at $\mathrm{pH}$ lower than 4, where most of the azo dye is in the pink, zwitterionic form and the selectivity of the reaction is not good. In the present investigation the azo dye obtained by diazo coupling with $p$ aminoacetophenone and $N$-(1-naphthyl)-ethylenediamine is protonated in the acidic media as the

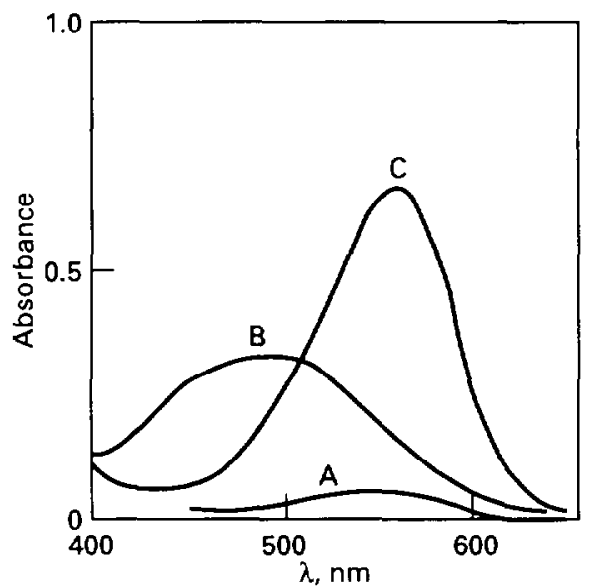

Fig. 2. Absorption spectra of the azo dye. Nitrite in aqueous solution: $1.0 \mu \mathrm{g}$ per $50 \mathrm{ml}$. (A) No concentration, $\mathrm{pH} 2.0$. (B) Membrane concentration, not acidified. (C) Membrane concentration, acidified. cation form. By using a large anion, the dye cation can be collected on the membrane filter as an ion association complex. Hexoic acid, benzene sulfonic acid, naphthyl sulfonic acid and sodium dodecyl sulfate were investigated as sources of large anions. It was found experimentally that sodium dodecyl sulfate is preferable for obtaining efficient collection.

\subsection{Effect of $p H$}

A study of the effect of $\mathrm{pH}$ on the relevant diazo coupling reaction and collecting on the membrane filter disclosed that diazotization of $p$-aminoacetophenone should be carried out in acidic solution and a constant and maximum absorbance is obtained at $\mathrm{pH} 0-3$; in the coupling of the diazonium cation with $N$-(1-naphthyl)ethylenediamine, the coloured compound has a constant absorbance in the $\mathrm{pH}$ range $1.0-3.0$; the ion associate of azo dye with dodecyl sulfate can be collected on the membrane filter at a $\mathrm{pH}$ between 1.0 an 5.0 without adjusting that of the solution. In practice, when $1.0 \mathrm{ml}$ of $p$-aminoacetophenone hydrochloride solution is added to a sample, the $\mathrm{pH}$ becomes about 2.0, it remains almost the same even when $N$-(1-naphthyl)ethylenediamine is added and after adding sodium dodecyl sulfate the $\mathrm{pH}$ of the aqueous solution is about $4-5$ (4.7 in practice). In order to minimize the effect of foreign ions in diazo coupling a $\mathrm{pH}$ of 2.0 is preferred.

\subsection{Effect of temperature}

Diazotization and coupling are usually carried out at $0-5^{\circ} \mathrm{C}$. However, reactions in this case proceed quantitatively at $10-30^{\circ} \mathrm{C}$. Therefore the reactions may be carried out at room temperature.

\subsection{Effect of standing time}

A complete diazotization requires at least 5 $\mathrm{min}$, and the coupling reaction requires $15 \mathrm{~min}$ or more. The azo compound formed in the aqueous phase is stable for at least $2 \mathrm{~h}$, and in the organic phase for $24 \mathrm{~h}$. 
Table 1

Effect of other factors on formation and collection of azo dye (for $50 \mathrm{ml}$ water sample)

\begin{tabular}{|c|c|c|c|}
\hline Variable & Tested & Optimum & Preferred \\
\hline Amount of $p$-aminoacetophenone $(\mathrm{ml})$ & $0.1-2.0$ & $0.8-2.0$ & 1.0 \\
\hline Amount of $N$-(1-naphthyl)-ethylenediamine (ml) & $0.1-2.0$ & $0.2-2.0$ & 1.0 \\
\hline Amount of sodium dodecyl sulfate $(\mathrm{ml})$ & $0.5-3.0$ & $1.5-2.5$ & 2.0 \\
\hline Amount of solvent (ml) & 5 & 5 & 5 \\
\hline Volume of washing water $(\mathrm{ml})$ & $10 \times(1-5)$ & $10 \times(1-3)$ & $10 \times 3$ \\
\hline Standing time after diazo coupling (min) & 5 & $10-30$ & 15 \\
\hline Stirring time after addition of surfactant ( $\mathrm{min}$ ) & $1.0-4.0$ & $2.0-4.0$ & 3.0 \\
\hline
\end{tabular}

\subsection{Membrane filter for collection}

Several filters of different types and with different pore sizes were examined for their usefulness for collecting the azo ion associate with nitrite. Nitrocellulose membrane filters are suitable because they readily dissolve in 2-methoxyethanol. Although any nitrocellulose membrane filter with pore sizes between 0.2 and $0.6 \mu \mathrm{m}$ can be used, $0.45 \mu \mathrm{m}$ filters are recommended because of their more stable absorbance of colour compound and acceptable filtration rate of about $50 \mathrm{ml}$ $\min ^{-1}$.

The analyte on a membrane filter should be washed three times with water to decrease the reagent blank.

\subsection{Solvent}

Water-miscible organic solvents were tested as solvents for the wet membranes. Dimethyl sulfoxide (DMSO), $N$ - $N$-dimethylformamide (DMF), acetone and 2-methoxyethanol readily dissolve the nitrocellulose and acetylcellulose membranes, but acetone is not recommended because of its high volatility. The colour intensity weakens obviously and decreases rapidly with time in DMSO and DMF. Absorbance of the colour compound is almost constant in 2-methoxyethanol for $24 \mathrm{~h}$ and is recommended as a proper solvent in the determination of nitrite. Other water-miscible solvents, such as ethanol, methanol and acetonitrile, will not dissolve the membrane under normal conditions.

\subsection{Effects of other factors}

Other factors, such as the amounts of reagents, time etc., recommended for the formation of azo dye and its collection on a membrane filter are shown in Table 1.

The volume of aqueous phase can be increased to $1000 \mathrm{ml}$ and good concentration is still obtained on condition that the amount of reagents should be increased in proportion to the $50 \mathrm{ml}$ water sample. For example, for treating a $250 \mathrm{ml}$ sample of water the amount of reagents should be increased five fold. For convenience $500 \mathrm{ml} \mathrm{sam-}$ ple of water is often used.

\subsection{Sensitivity, precision and linear relation}

Table 2 shows that microgram quantities of nitrite-nitrogen in $50 \mathrm{ml}$ of sample can be determined with satisfactory precision. The lower limit of determination (taken as three times the standard deviation of the blank) is about $0.002 \mu \mathrm{g}$ of nitrite-nitrogen per $100 \mathrm{ml}$ of sample

\subsection{Precision}

Absorbances of 11 runs for $0.6 \mu \mathrm{g} \mathrm{NO}_{2}^{-}$$\mathrm{N}(50 \mathrm{ml})$ are $0.423,0.424,0.403,0.417,0.416$, $0.406,0.416,0.406,0.417 . X=0.415 ; S=9.0 \times$ $10^{-3} ;$ C.V. $=2.17 \%$.

\subsection{Linear relation}

The regression equation in the range 0.1 $1.0 \mu \mathrm{g} \mathrm{NO}_{2}^{-}-\mathrm{N}$ is $y=-0.023+0.76 X$ with a relative coefficient of 0.9997 . 
Table 2

Reproducibility at different nitrite levels $s^{a}$

\begin{tabular}{|c|c|c|c|c|c|}
\hline \multirow{2}{*}{$\begin{array}{l}\text { Nitrite taken }(\mu \mathrm{g}) \\
\mathrm{NO}_{2}^{-}-\mathrm{N}\end{array}$} & \multicolumn{2}{|c|}{ Concn. of nitrite $\left(\mu \mathrm{g} \mathrm{dm}^{-3}\right)$} & \multicolumn{3}{|c|}{ Absorbance at $555 \mathrm{~nm}$} \\
\hline & as $\mathrm{N}$ & as $\mathrm{NO}_{2}^{-}$ & $\bar{X}$ & $s$ & RSD (\%) \\
\hline 0.2 & 4.0 & 13.1 & 0.121 & 0.005 & 3.8 \\
\hline 0.4 & 8.0 & 26.3 & 0.254 & 0.006 & 2.4 \\
\hline 0.6 & 12 & 39.4 & 0.403 & 0.007 & 1.7 \\
\hline 0.8 & 16 & 52.6 & 0.542 & 0.010 & 1.9 \\
\hline 1.0 & 20 & 65.7 & 0.636 & 0.011 & 1.7 \\
\hline
\end{tabular}

"Volume of sample: $50 \mathrm{~cm}^{3}$ : concentration factor: 10; No. of runs: 5 .

Table 3

Analyses of water samples and recovery of nitrite added to water sample

\begin{tabular}{lcllll}
\hline Sample & $\begin{array}{l}\text { Nitrite added } \\
\left(\mu \mathrm{g} \mathrm{dm}^{-3}\right. \\
\text { as nitrite })\end{array}$ & $\begin{array}{l}\text { Absorbance } \\
\text { at } 555 \mathrm{~nm}\end{array}$ & $\begin{array}{l}\text { Nitrite found } \\
(\mu \mathrm{g} \mathrm{dm})^{-3}, \\
\text { as nitrite })\end{array}$ & $\begin{array}{l}\text { Recovery of nitrite } \\
\left(\mu \mathrm{g} \mathrm{dm}^{-3}\right. \\
\text { as nitrite })\end{array}$ & $\%$ \\
\hline Ground water & 0 & 0.270 & 25.2 & - & - \\
& 13.1 & 0.419 & 38.2 & 13.0 & 99 \\
River water & 26.3 & 0.554 & 49.9 & - & 94 \\
Tapwater & 0 & 0.210 & 20.1 & 12.0 & - \\
Wellwater & 13.1 & 0.348 & 32.1 & - & - \\
\hline
\end{tabular}

\subsection{Effect of diverse components}

The effect of diverse components on the formation of azo dye and collecting of the ion associate by membrane filter was examined. In this study, the tolerance limit was set as the amount which caused an error of $\pm 5 \%$ in the recovery of $1 \mu \mathrm{g}$ of nitrite in a $50 \mathrm{ml}$ sample. At the nitrite level no interference was found with the following ions (where present the amount in milligrams and the form in which they were added are given in parantheses): $\mathrm{Na}^{+}(200, \mathrm{NaCl}) ; \mathrm{K}^{+}(200, \mathrm{KCl})$; $\mathrm{NH}_{4}^{-}\left(200, \mathrm{NH}_{4}^{+} \mathrm{Cl}\right) ; \mathrm{Ca}^{2+}\left(5, \mathrm{CaCl}_{2}\right) ; \mathrm{Mg}^{2+}(5$, $\left.\mathrm{MgCl}_{2}\right) ; \mathrm{Sr}^{2+}\left(2, \mathrm{SrCl}_{2}\right) ; \mathrm{Mn}^{2+}\left(2, \mathrm{MnSO}_{4}\right) ;$ $\mathrm{Cd}^{2+}\left(2, \mathrm{CdCl}_{2}\right) ; \mathrm{Cu}^{2+}\left(1, \mathrm{CuSO}_{4}\right) ; \mathrm{Pb}^{2+}(1$, $\left.\mathrm{Pb}\left(\mathrm{NO}_{3}\right)_{2}\right) ; \mathrm{Zn}^{2+}\left(1, \mathrm{ZnSO}_{4}\right) ; \mathrm{Hg}^{2+}(0.5 \mathrm{Hg}$ $\left.\left(\mathrm{NO}_{3}\right)_{2}\right) ; \mathrm{Co}^{2+} \quad\left(0.1 \quad \mathrm{CoCl}_{2}\right) ; \quad \mathrm{Mo}(\mathrm{VI}) \quad(0.1$, $\left.\mathrm{Na}_{2} \mathrm{MoO}_{4}\right) ; \mathrm{Al}^{3+}\left(2000, \mathrm{Al}\left(\mathrm{NO}_{3}\right)_{3}\right) ; \mathrm{Ga}^{3+}(1$, $\mathrm{Ga}\left(\mathrm{NO}_{3}\right) ; \mathrm{Cr}^{3+} \quad\left(1, \quad \mathrm{CrCl}_{3}\right) ; \quad \mathrm{As}(\mathrm{III}) \quad(0.1$, $\left.\mathrm{Na}_{3} \mathrm{AsO}_{3}\right) ; \mathrm{Sb}(\mathrm{V})\left(\mathrm{I}, \mathrm{Sb}\left(\mathrm{NO}_{3}\right)_{5}\right) ; \mathrm{Cl}(500, \mathrm{HCl}) ;$ $\mathrm{F}^{-}(40, \mathrm{NaF}) ; \mathrm{CH}_{3} \mathrm{COO}^{-}\left(30, \mathrm{CH}_{3} \mathrm{COONa}\right)$; $\mathrm{BO}_{2}^{-}\left(14, \mathrm{Na}_{2} \mathrm{~B}_{4} \mathrm{O}_{7}\right) ; \mathrm{Br}^{-}(8, \mathrm{NaBr}) ; \mathrm{I}^{-}(\mathrm{l}, \mathrm{KI})$;
$\mathrm{PO}_{4}^{3-}\left(200,\left(\mathrm{NaPO}_{3}\right)_{6}\right)$; citrate (30, citric acid); tartrate $(30$, tartric acid). Interference by large amounts of $5 \mathrm{mg}$ or more of $\mathrm{Fe}^{3+}$ can be masked by addition of sodium metaphosphate.

\subsection{Application of natural water samples}

The proposed method was applied for the analysis of river water and groundwater samples filtered through a $0.45 \mu \mathrm{m}$ membrane filter. Table 3 shows the analytical results of original samples and samples to which known quantities of nitrite has been added. Recovery of the added nitrite was nearly quantitative as shown in this Table.

\section{Acknowledgement}

The authors wish to express their heartfelt thanks to the Beijing Municipal Natural Science Foundation (BNSF) for financial support by Grant No. 1922005. 


\section{References}

[1] D.F. Boltz and J.A. Hoell, Colorimetric Determination of Nonmetals, Interscience. New York, 1978, p. 232.

[2] K. Toei and K. Kiyose, Anal. Chim. Acta, 88 (1977) 125.

[3] Tianze Zhou and Yongming Xie. Int. J. Environ. Anal. Chem., 15 (1983) 213.

[4] S. Taguchi, E. Ito-oka, K. Masuyama. I. Kasahara and K. Goto, Talanta, 32 (1985) 391
[5] C. Matsubara, Y. Yamamoto and K. Takamura, Analyst, 112 (1987) 1256.

[6] K. Goto and S. Taguchi, Anal. Sci., 9 (1993) 1.

[7] N. Hata, Q.Y. Lu, X.X. Gu, I. Kasahara, S. Taguchi and K. Goto, Bunseki Kagaku, 43 (1994) 461.

[8] APHA, AWWA and WPCF, Standard Methods for the Examination of Water and Wastewater, 14th edn.. Washingtun, DC. 1976, p. 434. 